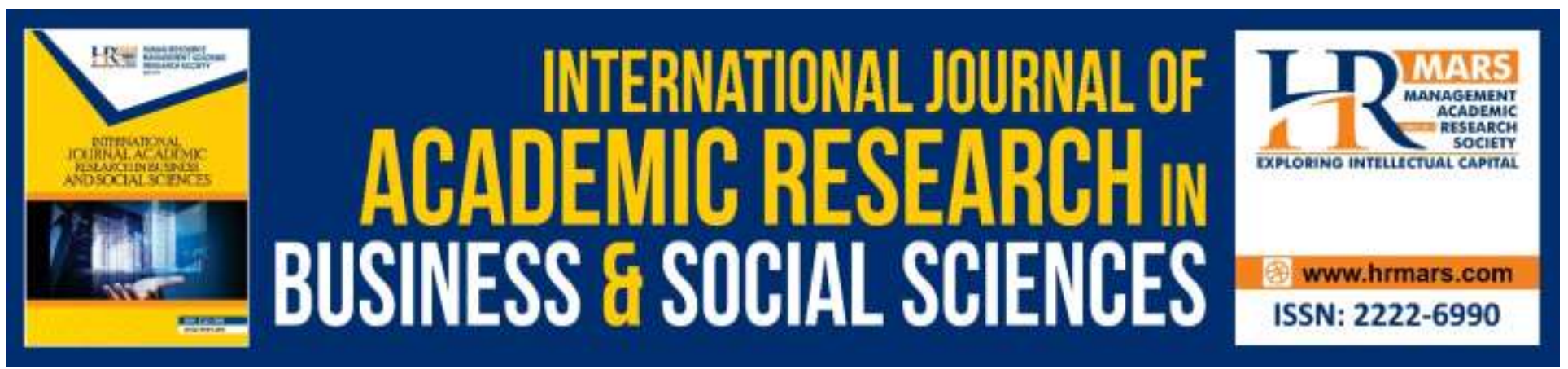

\title{
An Exploratory Factor Analysis in Measuring External Protective Factors of Resilience in Malaysian Adolescents.
}

Rose Manisah Sulong, Nor Aniza Ahmad, Norlizah Che Hassan, Zaida Nor Zainuddin, Maimunah Ismail

To Link this Article: http://dx.doi.org/10.6007/IJARBSS/v10-i3/7093 DOI:10.6007/IJARBSS/v10-i3/7093

Received: 02 February 2020, Revised: 22 February 2020, Accepted: 12 March 2020

Published Online: 29 March 2020

In-Text Citation: (Sulong et al., 2020)

To Cite this Article: Sulong, R. M., Ahmad, N. A., Hassan, N. C., Zainuddin, Z. N., \& Ismail, M. (2020). An Exploratory Factor Analysis in Measuring External Protective Factors of Resilience in Malaysian Adolescents. International Journal of Academic Research in Business and Social Sciences, 10(3), 797-810.

Copyright: (c) 2020 The Author(s)

Published by Human Resource Management Academic Research Society (www.hrmars.com)

This article is published under the Creative Commons Attribution (CC BY 4.0) license. Anyone may reproduce, distribute, translate and create derivative works of this article (for both commercial and non-commercial purposes), subject to full attribution to the original publication and authors. The full terms of this license may be seen

at: http://creativecommons.org/licences/by/4.0/legalcode

Vol. 10, No. 3, 2020, Pg. 797 - 810

http://hrmars.com/index.php/pages/detail/IJARBSS

JOURNAL HOMEPAGE

Full Terms \& Conditions of access and use can be found at http://hrmars.com/index.php/pages/detail/publication-ethics 


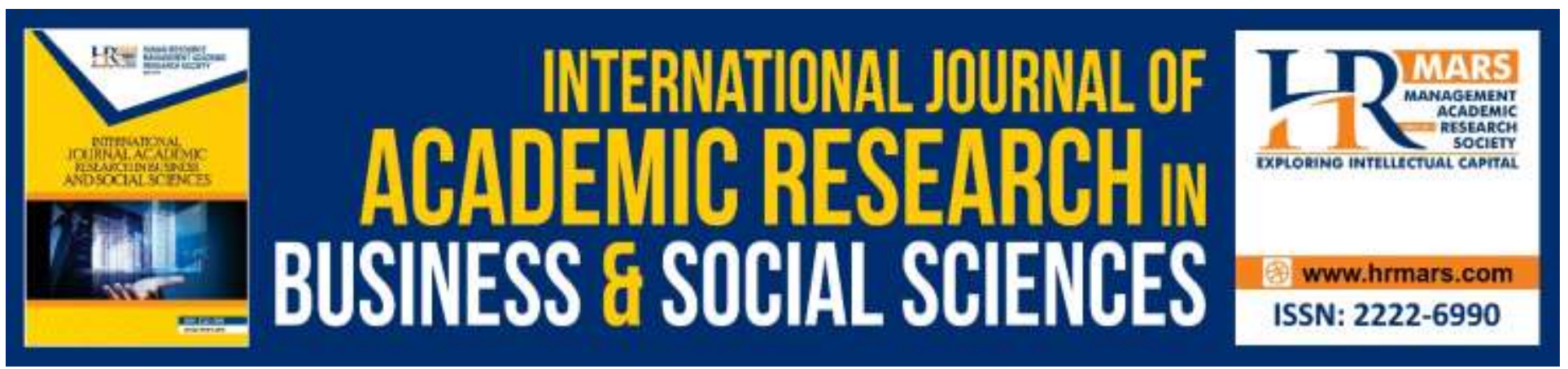

\title{
An Exploratory Factor Analysis in Measuring External Protective Factors of Resilience in Malaysian Adolescents.
}

\section{Rose Manisah Sulong, Nor Aniza Ahmad, Norlizah Che Hassan, Zaida Nor Zainuddin, Maimunah Ismail}

Faculty of Educational Studies, Universiti Putra Malaysia, 43400, UPM Serdang, Selangor, Malaysia Email: nor_aniza@upm.edu.my

\begin{abstract}
Adolescence is a period of stress that invites to psychosocial dysfunctional among adolescents. The effects of uncontrolled psychosocial dysfunctional can contribute to a variety of behavioral and emotional problems. This is alarming because statistics in Malaysia about psychosocial malfunction among adolescents show high rates when they are an important future asset to the nation. Literature suggest that research on protective factors of resilience can help to understand the strength of self as well as to highlight potential in adolescents. In this study, one set of questionnaires has been modified in the context of Malaysia and has been through the back-translation process, face and content validity as well as constructs validity. The construct validity of this study was analyzed using an exploratory factor analysis of 183 adolescents aged 16 years. Findings show that all constructs exceed the requirements for sufficient and significant samples for analysis of subsequent factor exploratory by extracting using the principal component of the analysis via varimax rotation. The analysis found that three factors were extracted for school external protective factors and home external protective factor and two factors have been extracted for peer external protective factor as suggested by Resilience Theory (Benard, 1991). Meanwhile, only two factors have been extracted for community external protection factor compared to the original three factors. The discussion and conclusion of this study are discussed in depth at the end of this article.
\end{abstract}

Keywords: Principal Component Analysis, Exploratory Factor Analysis, External Protective Factors of Resilience Measure, Adolescence, Malaysia.

\section{Introduction}

Development of sustainability among adolescents is very important as adolescents are valuable assets to the nation. However, the challenge to be faced is the reality of the existence of various disorders and pressures that occur in the stage of youth development which is considered a critical phase. As Compas (1993) claim the adolescents as a stressful period. In this phase there is a period of transition from childhood to 
INTERNATIONAL JOURNAL OF ACADEMIC RESEARCH IN BUSINESS AND SOCIAL SCIENCES

Vol. 10, No. 3, March, 2020, E-ISSN: 2222-6990 @ 2020 HRMARS

adulthood (Prever, 2006). It is a period that leads to the occurrence of stress, disorder, anxiety and even fear when an individual step into a new phase in his life and leave something that is customary for him like puberty, break up in the family and so on (Dawson \& Pooley, 2013).

Although some have succeeded during that period, there are still adolescents who have to deal with confusion, distress and conflict (Prever, 2006). During this transition, other than teenagers need to face and deal with physical and emotional changes (Kalashian, 2009), they also face various stress patterns every day. The stress pattern faced by these adolescents including stress in examinations and changes in these stress patterns has enhanced various psychosocial problems (Cowie, Boardman, Dawkins, \& Jennifer, 2004).

Psychosocial problems include emotional and behavioural disorder or are also known as internal disorders, commonly occurring such as depression and anxiety problems and external disorders such as delinquency, aggressive behaviour, education problems and truancy (Bista, Thapa, Sapkota, Singh, \& Pokharel, 2016). According to Bista, Thapa, Sapkota, Singh, \& Pokharel (2016), globally one out of ten adolescents experience at least one behavioural problem. In Malaysia, recent studies by Latiff, Tajik, Ibrahim, Bakar, \& Ali (2017) indicating the prevalence of psychosocial problems including internalizing disorders and externalizing disorders among adolescents aged 13 to 17 is high, where 24.7 percent are at abnormal levels and 20.7 percent are on the border line. The study also reported that 46 percent of them had depression, 59.1 percent had anxiety and 38.1 percent had a stress problem.

However, from a positive psychological perspective, emphasizing strengths, opportunities and assets is more useful than emphasis on stress and deficiency of individuals (Cowie et al., 2004). By focusing on strength or resilience, the potential of individuals, especially adolescent, can be identified and thus the development of sustainability among adolescents can be enhanced (Abu Bakar, Jamaluddin, Symaco, \& Darusalam, 2010). Thus, ongoing future studies examining the strength or resilience are needed in identifying protective factors of resilience that can help adolescents to remain survive despite facing odds. To conduct this study, a good questionnaire to measure the protective factors of resilience is very crucial. Hence, this paper aims to obtain a psychometrically sound questionnaire by assessing the validity and reliability of the questionnaire involved in this study into a specific group of adolescents.

\section{Literature Review}

Resilience is often defined as the ability of an adolescents to recover from the hardships and succeed in adjusting even in difficult circumstances. Eshel, Kimhi, Lahad and Leykin (2017) claims that in general, resilience is the ability to bounce back after going through a phase of suffering to a preadversity level of functioning. This adaptation process for successful adolescents involves the interconnectedness between internal strength and external factors that support the social environment around them (Johnson, 2008). Previous studies also show more strength or assets that adolescents have, much less risk patterns and more positive behaviours (Page \& Page, 2003). According to Dray, Bowman, Campbell, Freund, Hodder, Wolfenden et al. (2017), previous studies 
have identified that schools, peers, individuals, families and communities are important factors that contribute to health and behaviour during adolescence.

From the perspective of measurement, researchers in the field of resilience also pay attention and emphasize the assessment of protective factors that are alleged to protect the youth from the pressure they face (Connor \& Davidson, 2003; Wagnild \& Young, 1993). According to Dias and Cadime (2017), protective factors are the characteristics of individuals or the external environment that help adolescents to balance themselves from the risks they face. Considering the definitions of resilience by Holmes (2006) and Bakar (2012) who claim that resilience is seen as an internal factor that is strongly influenced by environmental factors and individual developmental processes, hence, this study focuses on external protective factors based on the Resilience Theory. This theory was proposed by Benard (1991) which explains the three external protective factors such as caring relationship, high expectations and meaningful participation in school, home, peer and community have a crucial role in helping to enhance internal strength in adolescents.

In Malaysia, extensive review of the literature on external protective factors researches showed that there is still a lack of questionnaire that has gone through the validity process to assess external protective factors of resilience among adolescents in Malaysia. The differences in geography, language, culture and religion found in Malaysia may lead to existing questionnaires that mostly come from Western countries not in line with the needs of locals. Since validity data and factor analysis on protective factors of resilience from local data are less, then, it becomes a requirement for a questionnaire that studies external protective factors for validity and factor analysis into Malay. The Malay language which is the mother tongue of most locals and national languages that used in their daily communication. Hence, a questionnaire on strong external protective factors and has undergone a legitimacy process in the context of Malaysian culture and can be a reference to future researchers will be conducted in this study. Specifically, the objective of the present study is to test the validity and reliability of questionnaire measuring external protective factors of resilience.

\section{Methodology}

Research Design and Respondent

This study is a cross-sectional study. The sample of this study involved 183 junior secondary school aged 16 in the East Coast of Peninsular Malaysia. Before the study, the permission to conduct the study was obtained from the authorities such as the Ministry of Education, the State Education Department and the school involved. Data collection was carried out by distributing questionnaires to respondents during school session with school counsellors' cooperation. The briefing was given before the session answered the questionnaire to ensure the collection of research data went smoothly.

\section{Survey of Instrument}

The questionnaire used in the present study was an adaptation and modification from previous research studies. The questionnaire consisted of 58 items measuring constructs with sub constructs of school (caring relationship, high expectation and meaningful participation), home (caring relationship, high expectation and meaningful participation), peers (caring relationship and high expectation/pro social) and community (caring relationship, high expectation and meaningful 
INTERNATIONAL JOURNAL OF ACADEMIC RESEARCH IN BUSINESS AND SOCIAL SCIENCES

Vol. 10, No. 3, March, 2020, E-ISSN: 2222-6990 @ 2020 HRMARS

participation). These constructs were measured through five-point Likert scale labelled as 1 (Not at all true about myself), 2 (Not true about myself), 3 (A little true about myself), 4 (Pretty much true about myself), and 5(Very true about myself).

\section{Validation Protocol}

In this study, the original questionnaire has been through several stages of validity in order to obtain the validity of the Malay version of the external protective factor of resilience.

\section{Translation}

Two language experts in both language, English and Malay have been involved in the translation process for this questionnaire. An expert has translated all items into Malay and a questionnaire in the Malay version has been produced. After that, the questionnaire was translated back into English by other experts to see the difference between the original version and the Malay version. Both experts have researched both versions and after taking into account aspects of language adjustment and cultural context adjustments, little modification has been made to the questionnaire.

\section{Content and Face Validation}

A total of six experts from the field of education, psychology and evaluation as well as measurement have been appointed for the purpose of evaluating the validity of the content and the validity of the questionnaire which has been through the process of translation. These experts have been conducting research on all items in the questionnaire to ensure that the suitability of this questionnaire is used to measure the external protective factor of resilience in Malaysian context. In order to reinforce the validity of the face, ten adolescents in the 16-year-old junior secondary school were asked to provide feedback on the layout of the questionnaire, the font size and the appropriate language fit for their age. The suggestions and comments received from them were used to improve the questionnaire before the questionnaire was adopted for the purpose of data collection.

\section{Construct and Factorial Validation}

To access the factorial validity of external protective factors of resilience, an exploratory factor analysis (EFA) was used. Generally, these statistical techniques are used for the purpose of scale development (Gorsuch, 1997; Yong \& Pearce, 2013). Specifically, expoloratory factor analysis is used to collect information about the intercorrelation of a set of variables (Pallant, 2001). A set of items is grouped into certain factors determined based on the relationship pattern between the items (Fabrigar, Wegener, Maccallum, \& Strahan, 1999). Items that have relationships with each other will form a factor. Thus, through exploratory factor analysis, the number of constructs and the factor structure will be identifiable (Suhr, 2006). In the factor analysis, the three main steps need to be addressed such as the suitability of the data for factor analysis, factor extraction, and rotation and factor interpretation (Pallant, 2001).

Exploratory Factor Analysis requires large data because large quantities of sample sizes reduce data errors (Yong \& Pearce, 2013). Because analysis factor is a multivariate statistical technique, this technique requires a large sample size of at least 150 for the exploration of the factor structure (Beavers, Lounsbury, Richards, Huck, Skolits \& Esquivel, 2013). Guadagnoli \& Velicer (1988) 
recommend that each factor has at least 10 to 12 items with the value of the factor loading is 0.4 and above, so the sample size of 150 or more is needed to achieve a reliable outcome. Based on these review of literature, 183 respondents who were used as samples during pilot study were sufficient for the purpose of analyzing the exploration factor of this research.

Kaiser-Meyer-Olkin Test of Sampling Adequacy (KMO) and Bartlett's Test of Sphericity statistics tests need to be done to assess the strength of the relationship between items. To determine whether a set of data is appropriate for factor analysis, the strength of the relationship between items is also examined through the correlation matrix. The research on correlation matrix table is made by referring to correlation coefficient value. Minimum coefficient of correlation is at least $r=0.3$ and above (Hair et al.,2010).

In assisting the researcher to determine the number of factors to be maintained, the Eigen value technique and the Catell scree test can be used (Yong \& Pearce, 2013). Eigen values indicate the total number of variances described by a factor (Pallant, 2001). The commonly used Eigen value is the Kaiser criteria which suggests only factors having the same Eigen value or greater than 1.0 that need to be maintained for further research (Pallant, 2001; Costello \& Osborne, 2005). Indirectly, factors with an Eigen value of less than 1.0 will be removed from the factor list (Piaw, 2014).

Meanwhile, Scree Test consists of Eigen value and factor (Yong \& Pearce, 2013). This scree plot is exhibited in the form of graphs showing a $x$ axis representing the number of factors and $y$ axis that showcase the value of Eigen (Beavers et al., 2013). Usually, the first factor has the highest Eigen value which gives meaning to this factor contributing to the highest variance value (Beavers et al., 2013). The number of factors that contribute to the large variance value to the dependent variable can be identified based on the graph which is vertical before it become horizontal (Chua Yan Piaw, 2014). Figure 1 below shows an example of three identified factors for the construct of a school's external protective factor based on a vertical graph before the graph is flat.

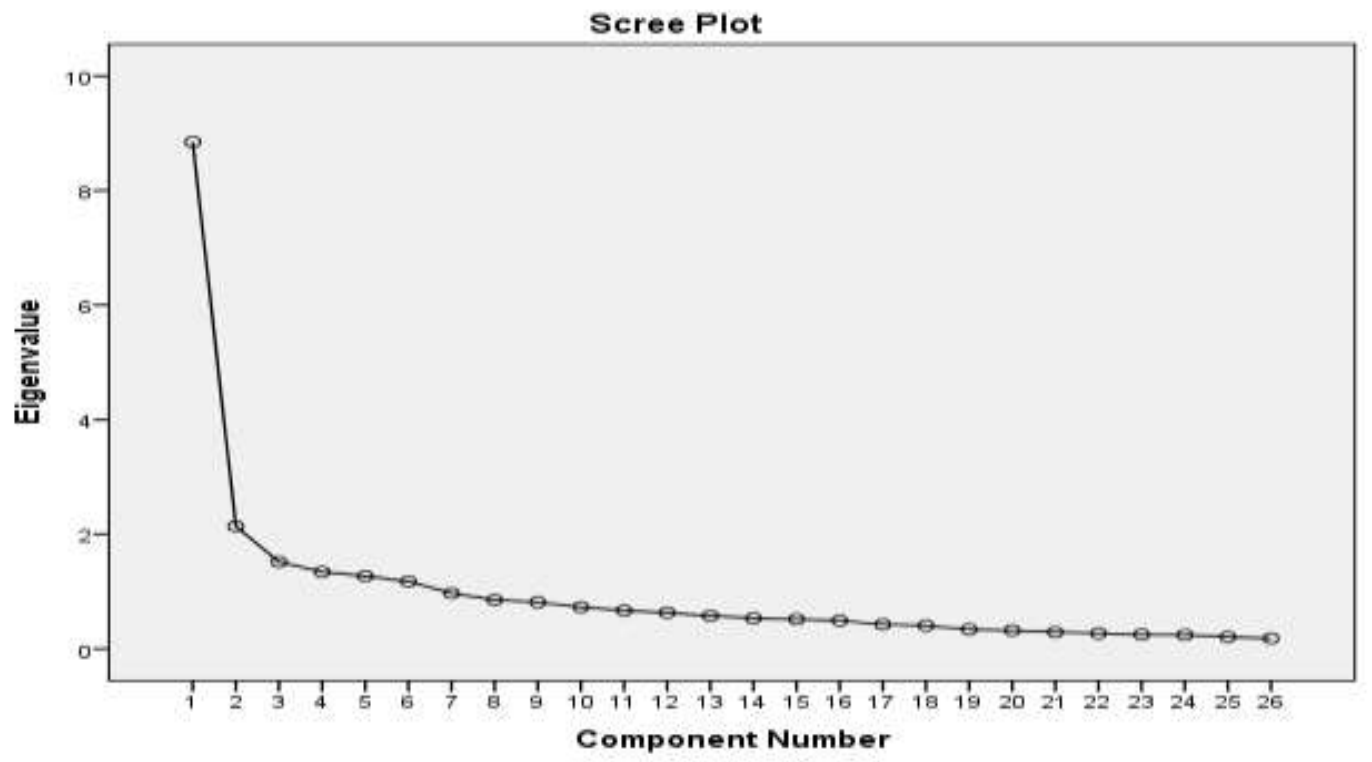

Figure 1 Examples of scree plot graphs for contruct of school external protective factors 
INTERNATIONAL JOURNAL OF ACADEMIC RESEARCH IN BUSINESS AND SOCIAL SCIENCES

Vol. 10, No. 3, March, 2020, E-ISSN: 2222-6990 @ 2020 HRMARS

Once the factors have been identified, the factor interpretation through the rotation process to these factors needs to be carried out (Pallant, 2001). The main purpose of the rotation is to classify a set of items to certain factors through statistical procedures in the EFA commonly used to extract the factor that is known as Principal component analysis (PCA) (Williams, Onsman \& Brown, 2010). This study used varimax rotation which considered as a best and widely used in Exploratory Factor Analysis studies (Fabrigar et al., 1999). Through varimax rotation, items that have a high correlation to each other are located on the axis of a factor loaded into the factor having a minimum rotation load of \pm 0.33 (Chua Yan Piaw, 2014). This means that items that can contribute $10 \%$ of the variance to a factor will be placed into that factor and the items that have been grouped into their respective factors can be referred to in the rotated component matrix table to be explained by the researchers themselves (Piaw, 2014).

\section{Results}

The result presented for this study was based on statistical analysis using the $23^{\text {rd }}$ edition of IBM Statistical Package of Social Sciences (SPSS) Software.

\section{Demographic Profile}

A total of 183 adolescents, which showed $60.1 \%$ were girls involved in the study. Most of these respondents lived with both parents (77.6\%) and most of them had siblings in a range of 3-5 people (38.3\%). In relation to parent's income, most parents of the respondents have a monthly income of less than RM1000 (46.4\%), followed by an income of around RM1000-RM2000 per month of 36.6\%. Socio demographic profiles are shown in Table 1. 
INTERNATIONAL JOURNAL OF ACADEMIC RESEARCH IN BUSINESS AND SOCIAL SCIENCES

Vol. 10, No. 3, March, 2020, E-ISSN: 2222-6990 @ 2020 HRMARS

Table 1: Socio Demographic Profiles of Adolescents $(n=183)$

\begin{tabular}{|c|c|}
\hline Socio-Demographic Profile & n (\%) \\
\hline \multicolumn{2}{|l|}{ Gender } \\
\hline Male & 73 (39.9\%) \\
\hline Female & $110(60.1 \%)$ \\
\hline \multicolumn{2}{|l|}{ School Location } \\
\hline Urban & $183(100 \%)$ \\
\hline \multicolumn{2}{|l|}{ Race } \\
\hline Malay & $183(100 \%)$ \\
\hline \multicolumn{2}{|l|}{ Staying with } \\
\hline Parents & $142(77.6 \%)$ \\
\hline Mother only & $30(16.4 \%)$ \\
\hline Father only & $3(1.6 \%)$ \\
\hline Grandfather and grandmother & $2(1.1 \%)$ \\
\hline Others & $6(3.3 \%)$ \\
\hline \multicolumn{2}{|l|}{ Number of siblings } \\
\hline $1-3$ & $54(29.5 \%)$ \\
\hline $3-5$ & $70(38.3 \%)$ \\
\hline $5-7$ & $33(18.0 \%)$ \\
\hline $7-9$ & $14(7.7 \%)$ \\
\hline More than 10 & $12(6.6 \%)$ \\
\hline \multicolumn{2}{|l|}{ Parents income } \\
\hline Less than RM1000 & $85(46.4 \%)$ \\
\hline RM1000-RM2000 & $67(36.6 \%)$ \\
\hline RM2001-RM3000 & $29(15.8 \%)$ \\
\hline RM3001-RM4000 & $1(5 \%)$ \\
\hline More than RM4000 & $1(5 \%)$ \\
\hline
\end{tabular}

\section{Factorial Validation of External Protective Factors of Resilience Questionnaire}

The discussion for the results are based on the objectives of the present study. The discussion started with the assessment of sample adequacy to conduct factor analysis, when the Kaiser-Meyer-Olkin Test (KMO) was investigated. As mentioned above, the minimum value suggesting adequate sampling to conduct factor analysis was 0.6 (Tabachnick \& Fidell, 1996). In the present study, the KMO value for school (0.857), home (0.891), peers (0.869) and community (0.900) were met. Therefore, factor analysis was able to perform due to adequate sampling based on KMO results for all construct. Meanwhile, Bartlett's Test of Sphericity for all the constructs of this study was significant at significant $\mathrm{p}<.05$. 
INTERNATIONAL JOURNAL OF ACADEMIC RESEARCH IN BUSINESS AND SOCIAL SCIENCES Vol. 10, No. 3, March, 2020, E-ISSN: 2222-6990 @ 2020 HRMARS

In this study, the school was measured using 14 items mainly related to three sub construct; caring relationship, high expectation and meaningful participation. Table 2 reports three factors with high factor loading ranged from 0.552 to 0.847 for all items. Factor 1 was labelled as caring relationship consisted of five items which are CR1 up to CR5. Meanwhile Factor 2 (high expectation) comprised of five items and they were HE6, HE7, HE8, HE9 and HE10. The last is Factor 3 which identified as meaningful participation constituted of four items namely MP11, MP12, MP13 and MP14.

Meanwhile, for home's construct, 16 items were used to measure sub construct. Six item were used to measure Factor 1 (caring relationship). The items are CR2, CR3, CR4, CR5, CR6 and CR7 with factor loading 0.451 to 0.833 . Meanwhile, Factor 2 was labelled as high expectation consisted with six items. The items that were placed within factor 2 were CR1, HE8, HE9, HE10, HE11 and HE12. Item namely CR1 had factor loading above 0.30 and the remaining five item with factor loading above 0.40 . According to Rossoni, Engelbert \& Bellegard (2016) and Shariman, Razak \& Noor (2014), item with factor loading less than 0.40 should be ignored and omitted, therefore, CR1 are dropped. The next factor is Factor 3 reflect meaningful participation which consisted of four items. Under meaningful participation, the items are MP13, MP14, MP15 and MP16 demonstrated factor loadings $>0.60$.

Next, to investigate whether 14 items of external protective factor (peers) indicate the two sub construct such as caring relationship and high expectation, the rotated component matrix of factor loading table was investigated. Based on Table 2, Factor 1 which is identified as caring relationship, constituted of seven item had showed high factor loadings ranged between 0.70 and 0.80 . The items that loaded in caring relationship's factor were CR1 to CR7. Meanwhile, Factor 2 reflects high expectation which consisted of six items. Items HE9 to HE14 fall within this factors with only two items (HE9, HE12) had factor loading above 0.50 and the remaining four had factor loadings above 0.70. However, one item namely HE8 was removed since it was loaded within Factor 3 which is unknown factor. Therefore, this item and factor was deleted and consequently 13 items remained.

Finally, to access factor validation for community external protective factor, the findings investigated was based on the rotated component matrix table. Table 2 showed that Factor 1 consisted of 11 items, Factor 2 with six items, while Factor 3 constituted of two items. Items fall within Factor 1 were CR1, CR2, CR3, CR4, CR5, HE6, HE7, HE8, HE9, HE10 and HE11. Interesting findings showed that items within original factor such as caring relationship and high expectation falls into same factors. This finding was in line with a previous study by Hanson and Kim (2007) who suggested that factors that incorporate items of 'caring relationship' and 'high expectation' are called 'supportive relationships'. Therefore, in the present study, this factor named as a supportive relationship. Meanwhile, for Factor 2 which depicts constructs for meaningful participation, items that fall within these factors are as many as six items (MP12 to P19) with a factor loading $>0.50$. On the other hand, there are two items were loaded on Factor 3 namely MP14 and MP15. Because of factor requires at least three items or five items to form one factor, factor with two items is considered as unreliable and should be deleted. The number of items is insufficient to form one factor because each stable factor must have at least three or five items (Costello \& Jason, 2005). Therefore, for this construct (community) only 17 items were remained consequently. 
INTERNATIONAL JOURNAL OF ACADEMIC RESEARCH IN BUSINESS AND SOCIAL SCIENCES Vol. 10, No. 3, March, 2020, E-ISSN: 2222-6990 @ 2020 HRMARS

Table 2: Component Matrix of External Protective Factor of Resilience

\begin{tabular}{|c|c|c|c|c|}
\hline Construct & Original Factor & Factor 1 & Factor 2 & Factor 3 \\
\hline \multirow[t]{14}{*}{ School } & CR1 & 0.804 & & \\
\hline & CR2 & 0.633 & & \\
\hline & CR3 & 0.663 & & \\
\hline & CR4 & 0.552 & & \\
\hline & CR5 & 0.670 & & \\
\hline & HE6 & & 0.594 & \\
\hline & HE7 & & 0.650 & \\
\hline & HE8 & & 0.777 & \\
\hline & HE9 & & 0.724 & \\
\hline & HE10 & & 0.684 & \\
\hline & MP11 & & & 0.633 \\
\hline & MP12 & & & 0.823 \\
\hline & MP13 & & & 0.847 \\
\hline & MP14 & & & 0.640 \\
\hline Construct & Original Factor & Factor 1 & Factor 2 & Factor 3 \\
\hline \multirow[t]{16}{*}{ Home } & CR2 & 0.833 & & \\
\hline & CR3 & 0.766 & & \\
\hline & CR4 & 0.451 & & \\
\hline & CR5 & 0.471 & & \\
\hline & CR6 & 0.599 & & \\
\hline & CR7 & 0.586 & & \\
\hline & CR1 & & $0.359^{*}$ & \\
\hline & HE8 & & 0.730 & \\
\hline & HE9 & & 0.681 & \\
\hline & HE10 & & 0.780 & \\
\hline & HE11 & & 0.443 & \\
\hline & HE12 & & 0.598 & \\
\hline & MP13 & & & 0.639 \\
\hline & MP14 & & & 0.629 \\
\hline & MP15 & & & 0.684 \\
\hline & MP16 & & & 0.674 \\
\hline Construct & Original Factor & Factor 1 & Factor 2 & Factor 3 \\
\hline \multirow[t]{14}{*}{ Peers } & CR1 & 0.765 & & \\
\hline & CR2 & 0.822 & & \\
\hline & CR3 & 0.841 & & \\
\hline & CR4 & 0.817 & & \\
\hline & CR5 & 0.799 & & \\
\hline & CR6 & 0.778 & & \\
\hline & CR7 & 0.812 & & \\
\hline & HE8 & & & $0.920^{*}$ \\
\hline & HE9 & & 0.561 & \\
\hline & HE10 & & 0.714 & \\
\hline & HE11 & & 0.758 & \\
\hline & HE12 & & 0.539 & \\
\hline & HE13 & & 0.726 & \\
\hline & HE14 & & 0.705 & \\
\hline Construct & Original Factor & Factor 1 & Factor 2 & Factor 3 \\
\hline \multirow[t]{6}{*}{ Community } & CR1 & 0.752 & & \\
\hline & CR2 & 0.700 & & \\
\hline & CR3 & 0.768 & & \\
\hline & CR4 & 0.741 & & \\
\hline & CR5 & 0.796 & & \\
\hline & HE6 & 0.777 & & \\
\hline
\end{tabular}


INTERNATIONAL JOURNAL OF ACADEMIC RESEARCH IN BUSINESS AND SOCIAL SCIENCES

Vol. 10, No. 3, March, 2020, E-ISSN: 2222-6990 @ 2020 HRMARS

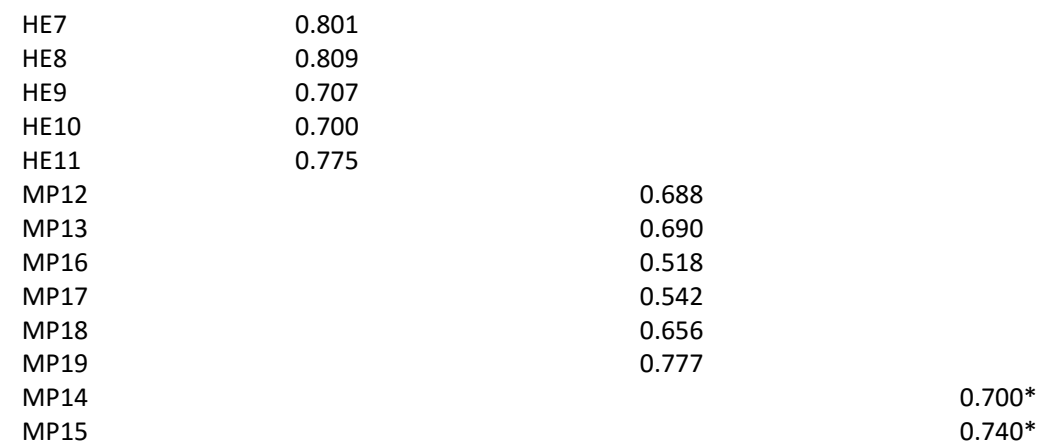

Note: Extraction Method: Principal Component Analysis. Rotation Method: Varimax with Kaiser. * Item deleted, $\mathrm{CR}=$ Caring Relationship, $\mathrm{HE}=$ High Expectation, $\mathrm{MP}=$ Meaningful Participation.

\section{Internal Consistency of External Protective Factors of Resilience Questionnaire}

The internal consistency of this questionnaire or remaining items after conducted EFA was measured using the Cronbach's alpha. The overall internal consistency seemed to be highly promising which is 0.942. The internal consistency values of the four constructs of the present study ranged from 0.870 to 0.914 . As the Cronbach alpha values showed higher than 0.70 which indicate they were good and acceptable (Hair, 2010). Table 3 report the internal consistency of the overall scale and also for each constructs of external factors of resilience questionnaire.

Table 3: Internal Consistencies of each constructs

\begin{tabular}{lcc}
\hline Constructs & No. of Item & Cronbach alpha $(\boldsymbol{\alpha})$ \\
\hline Overall & 59 & 0.942 \\
School & 14 & 0.870 \\
Home & 15 & 0.876 \\
Peers & 13 & 0.883 \\
Community & 17 & 0.914 \\
\hline
\end{tabular}

\section{Discussion and Conclusion}

The purpose of the present study is to provide validity and reliability of the questionnaire that measure external protective factors of resilience through exploratory factor analysis (EFA) as well as Cronbach's Alpha. The construct and sub constructs involved in this study were school external protective factor (caring relationship, high expectation and meaningful participation), home external protective factor (caring relationship, high expectation and meaningful participation), peers external protective factor (caring relationship and high expectation/pro social) and community external protective factor (caring relationship, high expectation and meaningful participation). The findings indicate that most items were grouped into the respective factors as suggested by theoretical construct of Benard (1991). Overall, the items of the present study was able to measure construct and sub constructs of external protective factors of resilience adopted from Benard's Resilience Theory especially for school, home and peers. 
The findings provide evidence of validity of the questionnaire measuring the external protective factors of resilience. In addition, this questionnaire shows evidence of internal consistency reliability. The findings also show that the questionnaire is a valid and reliable instrument that can be used to measure the external protective factors of resilience among Malaysian adolescents. Even though the result for community external protective factors differed from the theory, but according to Nearchou, Stogiannidou \& Kiosseoglou (2014), differences in the loading of items on uneven dimensions across multicultural populations may be related to the cultural discrepancy. It is proven that this study, which used questionnaires of external protective factors of resilience in the Malay language version demonstrates findings that are consistent with previous studies using the English version questionnaires. Therefore, the questionnaire is a psychometrically sound questionnaire in measuring external protective factors of resilience.

However, as with other empirical studies, this study has certain limitations. First, this study involves only 16-year-olds adolescents. Therefore, generalization of research findings should be done with caution. It is suggested that future studies will involve different age groups of adolescents so that the findings can be discussed more thoroughly. This study is also limited to adolescents who lived in urban areas and only Malay were involved. The findings will be more interesting to discuss if future studies involve samples from rural areas and also included other races found in Malaysia such as Chinese, Indian and others.

\section{Acknowledgement}

The researchers would like to thank the Ministry of Education Malaysia, schools and respondents who involved in this study.

\section{Corresponding Author}

Corresponding Author's Name: Nor Aniza Ahmad (PhD)

Department of Foundations of Education, Faculty of Educational Studies, Universiti Putra Malaysia, 43400 UPM Serdang, Selangor, Malaysia.

Email:nor_aniza@upm.edu.my

\section{References}

Abu Bakar, A., Jamaluddin, S., Symaco, L., \& Darulsalam, G. (2010). Resiliency among secondary school students in Malaysia: Assessment of the measurement model. International Journal of Educational and Psychological Assessment, 4, 68.

Bakar, A. A. (2012). Developing a model for the role of religiosity and self-efficacy in the ability to bounce back among adolescents: Ex post facto research. World Applied Sciences Journal, 16 (5), 721-725.

Beavers, A. S., Lounsbury, J. W., Richards, J. K., Huck, S. W., Skolits, G. J., \& Esquivel, S. L. (2013). Practical considerations for using exploratory factor analysis in educational research. Practical assessment, research \& evaluation, 18.

Benard, B. (1991). Fostering resiliency in kids: Protective factors in the family, school, and community. Bista, B., Thapa, P., Sapkota, D., Singh, S. B., \& Pokharel, P. K. (2016). Psychosocial Problems among Adolescent Students: An Exploratory Study in the Central Region of Nepal. Frontiers in Public 
INTERNATIONAL JOURNAL OF ACADEMIC RESEARCH IN BUSINESS AND SOCIAL SCIENCES

Vol. 10, No. 3, March, 2020, E-ISSN: 2222-6990 @ 2020 HRMARS

Health, 4, 158. doi.org/10.3389/fpubh.2016.00158.

Chua, Y. P. (2014). Ujian regresi, analisis factor dan analisis SEM. McGraw-Hill Education (Malaysia).

Connor, K. M., \& Davidson, J. R. (2003). Development of a new resilience scale: The Connor-Davidson resilience scale (CD-RISC). Depression and anxiety, 18(2), 76-82.

Compas, B. E. (1993). Promoting Positive Mental Health during Adolescence. Promoting the Health of Adolescents.New Directions for the Twenty-First Century, 159-179 (p. 403). New York: Oxford University Press.

Constantine, N. A., Benard, B., \& Diaz, M. (1999). Measuring Protective Factors and Resilience Traits in Youth: The Healthy Kids Resilience Assessment. Seventh Annual Meeting of the Society for Prevention Research. LA, New Orleans.

Costello, Anna, B., \& Osborne, J. (2005). Best practices in exploratory factor analysis: four recommendations for getting the most from your analysis. Practical Assessment Research \& Evaluation, 10(7). http://pareonline.net/getvn.asp?v=10\&n=7.

Cowie, H., Boardman, C., Dawkins, J., \& Jennifer, D. (2004). Emotional Health and Well Being.A Practical Guide for Schools. London: Paul Chapman Publishing.

Dawson, M., \& Pooley, J. A. (2013). Resilience: The Role of Optimism, Perceived Parental Autonomy Support and Perceived Social Support in First Year University Students. Journal of Education and Training Studies, 1(2). doi.org/10.11114/jets.v1i2.137.

Dias, P. C., \& Cadime, I. (2017). Protective factors and resilience in adolescents: The mediating role of self regulation. Psicologia Educativa, 23(1), 37-43. doi.org/10.1016/j.pse.2016.09.003.

Dray, J., Bowman, J., Campbell, E., Freund, M., Hodder, R., Wolfenden, L., Richards, J., Leane C, Green, S., Lecathelinais, C., Oldmeadow, C., Attia, J., Gillham \& K., Wiggers, J. (2017). Effectiveness of a pragmatic school-based universal intervention targeting student resilience protective factors in reducing mental health problems in adolescents. Journal of adolescence, 57(Suplement C), 7489. doi.org/10.1016/j.adolescence.2017.03.009.

Eshel, Y., Kimhi, S., Lahad, M., \& Leykin, D. (2017). Individual attributes as predictors of protective and risk components of resilience under continuing terror attacks: A longitudinal study, Personality and indivivual differences, 114, 160-166.

Fabrigar, L. R., Wegener, D. T., MacCallum, R. C., \& Strahan, E. J. (1999). Evaluating the use of exploratory factor analysis in psychological research. Psychological methods, 4(3), 272.

Guadagnoli, E., \& Velicer, W. F. (1988). Relation of sample size to the stability of component patterns. Psychological bulletin, 103(2), 265.

Gorsuch, R. L. (1997). Exploratory factor analysis: Its role in item analysis. Journal of personality assessment, 68(3), 532-560.

Hanson, T. L., \& Kim, J. O. (2007). Measuring Resilience and Youth Development: The Psychometric Properties of the Healthy Kids Survey. Issues \& Answers. REL 2007-No. 34. Regional Educational Laboratory West.

Hair, J. F., Black, W. C., Babin, B. J., \& Anderson, R. E. (2010). Multivariate Data Analysis $7^{\text {th }}$ Edition Pearson Prentice Hall.

Holmes, K. (2006). Adolescent resilience: The influence of family relationships and their impact on resilient outcomes. Ph.D Thesis. Fordham University.

Johnson, B. (2008). Teacher-student relationships which promote resilience at school: a micro-level analysis of students' views. British Journal of Guidance \& Counselling, 36(4), 385-398. doi: 
INTERNATIONAL JOURNAL OF ACADEMIC RESEARCH IN BUSINESS AND SOCIAL SCIENCES

Vol. 10, No. 3, March, 2020, E-ISSN: 2222-6990 C 2020 HRMARS

org/10.1080/03069880802364528.

Kalashian, C. (2009). Mental Health Services in Secondary Schools. (Doctoral dissertation). California state University.

Latiff, L. A., Tajik, E., Ibrahim, N., Bakar, A. A. S., \& Ali, S. S. A. (2017). Psychosocial problem and its associated factors among adolescents in the secondary schools in Pasir Gudang, Johor. Malaysian Journal of Medicine and Health Sciences, 13(1), 35-44.

Nearchou, F. A., Stogiannidou, A., \& Kiosseoglou, G. (2014). Adaptation and psychometric evaluation of a resilience measure in Greek elementary school students. Psychology in the Schools, 51(1), 58-71. doi: 10.1002/pits.21732

Page, R. M., \& Page, T. S. (2003). Fostering emotional well-being in the classroom. Jones \& Bartlett Learning.

Pallant, J. (2001). SPSS Survival Guide: A Step by step guide to data analysis using SPSS. Australia: Allen \& Unwin.

Prever, M. (2006). Mental Health in Schools.A Guide to Postoral and Curriculum Provision. Paul Chapman Publishing.

Rossoni, L., Engelbert, R., \& Bellegard, N. L. (2016). Normal science and its tools: Reviewing the effects of exploratory factor analysis in management. Revista de Administracao (Sao Paulo), 51(2), 198211.

Shahriman, T. P. N. T., Razak, N. A., \& Noor, N. F. M. (2014). An exploratory factor analysis of marginalized youths' access and use of English language digital contents. Procedia-Social and Behavioral Sciences, 118, 483-488.

Suhr, D. D. (2006). Exploratory or confirmatory factor analysis?.

Tabachnick, B. G., \& Fidell, L. S. (1996). Using multivariate statistics. Harper Collins. New York.

Wagnild, G., \& Young, H. (1993). Development and psychometric. Journal of nursing measurement, $1(2), 165-178$.

Williams, B., Onsman, A., \& Brown, T. (2010). Exploratory factor analysis: A five-step guide for novices. Australasian Journal of Paramedicine, 8(3). Yong, A. G., \& Pearce, S. (2013).

Yong, A. G., \& Pearce, S. (2013). A beginner's guide to factor analysis: Focusing on exploratory factor analysis. Toturials in quantitative methods for psychology, 9(2), 79-94. 